\title{
A case of atypically located leiomyoma mimicking axillary lymphadenomegaly
}

\author{
Mehmet Nuri Cevizci ${ }^{1}$, Ali Fettah², Mehmet Eşref Kabalar ${ }^{3}$ \\ Departments of ${ }^{1}$ Pediatric Surgery, ${ }^{2}$ Pediatric Hematology and Oncology and ${ }^{3}$ Pathology, Erzurum Regional Training and \\ Research Hospital, Erzurum, Turkey. E-mail: drcevizci77@yahoo.com \\ Received: 13th April 2017, Revised: 9th June 2017, Accepted: 10th July 2017
}

SUMMARY: Cevizci MN, Fettah A, Kabalar ME. A case of atypically located leiomyoma mimicking axillary lymphadenomegaly. Turk J Pediatr 2018; 60: 319-321.

Leiomyomas are benign smooth muscle tumors rarely seen in children and may occur anywhere in the body containing smooth muscle. Here, we report a case of a 4-year-old girl presenting with swelling in the left axillary region and with pain during arm movements. The solid mass in the axillary region was totally excised. The patient was discharged without complications on the same day.

Key words: leiomyoma, axillary mass, child.

Leiomyoma is a benign smooth muscle tumor that may occur anywhere in the body containing smooth muscle. It is very rare in children. The lesions are divided into three categories - cutaneous, vascular and deep soft tissue leiomyomas. It is difficult to diagnose these masses clinically and radiologically. Definite diagnosis is generally made at histopathological examination after surgery. Although solitary soft tissue leiomyomas are very rare, particularly in childhood, a limited number of cases have been reported, the majority in adults. ${ }^{1,2} \mathrm{We}$ describe a leiomyoma atypically located in the axillary region.

\section{Case Report}

A 4-year-old girl presented with swelling in the left axillary region and with pain during arm movements that had failed to respond to medical treatment over the previous year. The patient's history showed that she had used antibiotherapy several times due to the existing lesion, but that this had not decreased in size. A semi-mobile, moderately hard mass, approximately $20 \times 10 \mathrm{~mm}$ in size, causing pain with arm abduction was determined in the left axillary region on physical examination. Other system examinations were unremarkable. Complete blood count, peripheral blood smear examination, blood biochemistry, erythrocyte sedimentation rate and $\mathrm{C}$-reactive protein values were within normal limits. A soft tissue mass compatible with lymphadenomegaly with peripheral blood flow, containing occasional calcifications with a thick, rounded cortex, $20 \times 11 \mathrm{~mm}$ in size, was reported in the left axillary region on superficial ultrasonography (USG). Abdominal USG was normal. Due to the patient's symptoms persisting for one year and the occasional pain experienced, we decided to excise the mass. The solid mass in the axillary region, approximately $25 \times 20 \times 10$ $\mathrm{mm}$ in size, the margins of which were visible and which was located over the muscle without invading it, was totally excised. The patient was discharged without complications on the same day. The pain in the left arm improved after the operation. When the mass was dissected during surgery, it was closely associated with and adhered to occasional nerve branches. The nerve branches were easily separated from the mass, and no invasion findings were observed. Immunohistochemical staining revealed a mass compatible with leiomyoma, staining negative with $\mathrm{S} 100$ and staining positive with smooth muscle actin (SMA), vimentin and desmin, while histopathological examination revealed central calcifications, exhibiting bunches of fusiform cells and swirls on mass sections but no necrosis or mitosis (Fig. 1). No similar lesions were determined in other locations where thoracoabdominal 

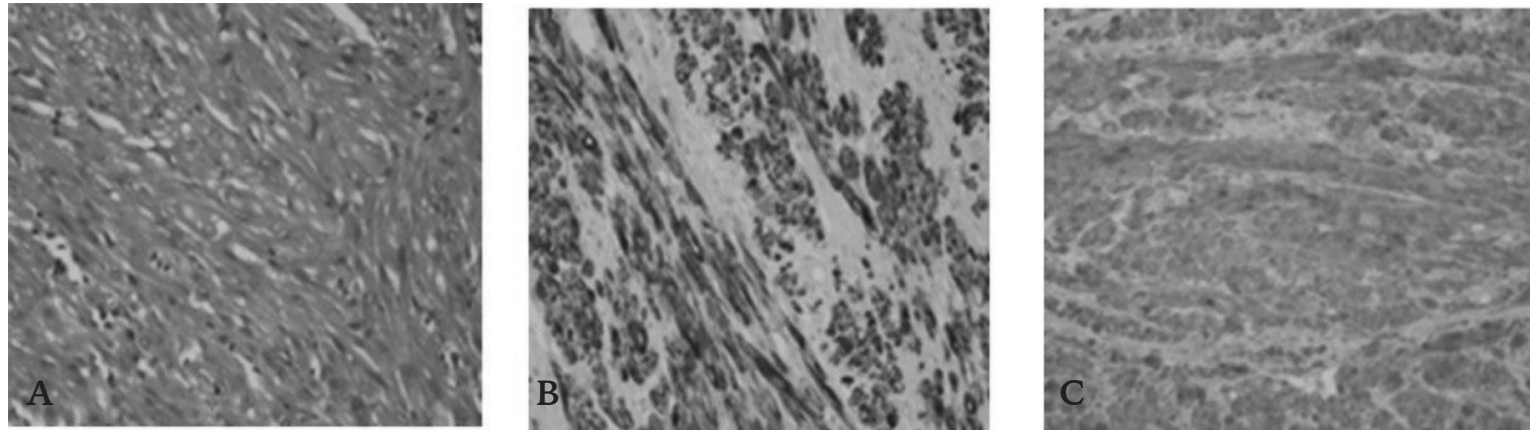

Fig. 1. Histopathological findings. A; Smooth muscle cells creating fusiform bunches and swirls (H\&E, x40). B; Actin positive stained cells. C; Desmin positive stained cells. (H\&E=hematoxylin- eosin, SMA = smooth muscle actin)

computerized tomography was performed following diagnosis of leiomyoma. No symptom or recurrence was observed at 2-year followup after excision. Consent was obtained from parents.

\section{Discussion}

Leiomyomas are benign smooth muscle tumors rarely seen in children. They constitute $4.4 \%$ of all benign soft tissue tumors. ${ }^{3}$ These slowgrowing tumors can appear anywhere in the body containing smooth muscle. Leiomyomas are most common in the gastrointestinal system and the uterus. ${ }^{4}$ Leiomyoma was first described by Virchow in 1854, and was later divided into three categories - cutaneous, vascular and deep soft tissue - by Kloepferet al. ${ }^{5}$ Vascular and deep soft tissue leiomyomas are generally seen at the ages of 30-40, and more commonly in women. No direct association has been shown between the prevalence of solitary form cutaneous and subcutaneous leiomyomas and age or race. ${ }^{6}$ Deep non-vascular leiomyomas are generally solitary and are very rare in the literature. In a study of 21 cases of leiomyoma of deep soft tissue, Misumi et al. ${ }^{7}$ reported an age range of 3-62 years (mean 25 years) and that these were twice as common in females. They also reported that the mass was located in the extremities in approximately half of cases, and that only one case involved multiple lesions. The fact that tumors in the extremities can be detected early through external observation and that they cause greater pain when exposed to pressure and trauma make it possible to diagnose and treat such tumors early. In our case, the patient was monitored for an extended period since the mass was located in the axillary lymph node region, and reactive lymph node was suspected due to the absence of any change in dimensions at serial USG follow-ups. The patient had received non-specific antibiotic therapy on several occasions. We decided to excise the lesion since it exhibited typical lymphadenopathy characteristics and caused chronic pain symptoms during arm movement.

In addition to lymphadenopathy, inflammation and lipoma, breast carcinoma-related lymph node metastasis and fibroadenoma should also be considered for the differential diagnosis of axillary masses, particularly in adults. ${ }^{4}$ Possibilities other than lymphadenopathy were not considered at differential diagnosis for our patient due to her age and clinical condition. Symptoms in leiomyomas are not specific, and the most common finding is pain. Since pain occurs due to the slowly growing mass compressing surrounding nerve tissues, subcutaneous and deep leiomyomas may not produce findings in the short term. Since pain in cutaneous leiomyomas occurs as a result of exposure to cold air in addition to pressure, this symptom appears earlier and more frequently. In addition, contractions in smooth muscle cells in leiomyomas have also been reported to cause pain directly. ${ }^{4}$ In our case, the mass was seen to be close to the nerve fibers during surgery, and the movement-related pain was attributed to this.

The pathogenesis of leiomyomas is unclear. Goodman et al. ${ }^{8}$ suggested that deep leiomyomas derive from the remains of smooth muscle cells that have not completed maturation (undifferentiated) or from mesenchymal cells. Most of these tumors may not be detected until they produce findings with pain symptoms. Even if detected, they may be overlooked by the patient or physician because they 
cause no clinical symptoms. Calcification has been reported in some isolated deep tissue leiomyomas. ${ }^{8}$ Calcifications concentrated in the center of the tumor were determined at histopathological examination in our case. It is difficult to differentiate leiomyomas from leiomyosarcoma, lipoma, schwannoma, neurofibroma and hemangioma in macroscopic and radiological terms. ${ }^{9}$ Leiomyosarcoma has been reported to develop from approximately $0.5 \%$ of these masses. ${ }^{4,10}$ Due to the possibility of malignant transformation, total excision of solitary and single masses in particular, together with the surgical margins, is recommended. ${ }^{4}$ Definite diagnosis in most cases is only possible through histopathological examination after surgical excision. Atypical cells, necrosis and mitotic activity at histopathological investigation must be interpreted as a warning sign in terms of malignant formation and post-surgical recurrence. Recurrence of leiomyomas with distinct surgical margins and that have been totally excised is rare. The surgical margin in our case was distinct, and the mass was totally excised. No atypical cells, necrosis or mitotic activity were observed at histopathological examination, and there was no recurrence at 2-year follow-up.

In conclusion, although leiomyoma is a pathology that may be encountered anywhere containing smooth muscle, deep soft tissue leiomyoma in the axillary lymph nodes is very rare in childhood. Although the majority of masses in the axillary lymph nodes appear as lymphadenitis due to infectious causes, leiomyoma and potential tumoral structures must be considered at differential diagnosis. It is very important to determine the margins when extracting the mass, and in order to prevent recurrence, the mass need to be totally excised.

\section{REFERENCES}

1. Naguib NN, Nour-Eldin NE, Serag-Eldin F, et al. Role of uterine artery Doppler in the management of uterine leiomyoma by arterial embolization. Ultrasound Obstet Gynecol 2012; 40: 452-458.

2. Clement PB. The pathology of uterine smooth muscle tumors and mixed endometrial stromal-smooth muscle tumors: A selective review with emphasis on recent advances. Int J Gynecol Pathol 2000; 19: 39-55.

3. Lopez-Barea F, Rodriguez-Peralto JL, Burgos E, Gonzalez-Lopez J. Calcified leiomyoma of deep soft tissue. Report of a case in childhood. Virchows Arch 1994; 425: 217-220.

4. Kim HJ, Baek SO, Rha EY, Lee JY, Han HH. Leiomyoma originating from axilla: A rare case report and differential diagnosis Medicine (Baltimore) 2016; 95: e4402.

5. Kloepfer, HW, Krafchuk J, Derbes V, Burks J. Hereditary multiple leiomyoma of the skin. Am J Hum Genet 1958; 10: 48-52.

6. Bommireddy B, Gurram V. Deep soft tissue leiomyoma of forearm: A case report and review of literature. J Clin Diagn Res 2016; 10: RD03-5.

7. Misumi S, Irie T, Fukuda K, Tada S, Hosomura Y. A case of deep soft tissue leiomyoma: CT and MRI findings. Radiation Medicine 2000; 18: 253-256.

8. Goodman AH, Briggs RC. Deep leiomyoma of an extremity. J Bone Joint Surg Am 1965; 47: 529-532.

9. RamachandranR, Rangaswami R, Raja DK, Shanmugasundaram G. Deep soft-tissue leiomyoma of the forearm mimicking a primary bone tumor of the ulna. Radiol Case Rep 2015; 9: 960.

10. Parker WH, Fu YS, Berek JS. Uterine sarcoma in patients operated on for presumed leiomyoma and rapidly growing leiomyoma. Obstet Gynecol 1994; 83: 414-418. 